\title{
Exploration and Application of Smart Site in Construction Quality Management
}

\author{
Sumo Huo* \\ Department of Economic Management, North China Electric Power University, Baoding, China \\ *Corresponding author: Summer@ncepu.edu.cn
}

Keywords: BIM, Construction quality, Informationize, Smart construction site.

\begin{abstract}
With the continuous development of the construction industry, the construction quality has become an unavoidable topic. As the concentrated embodiment of smart city in engineering field, smart construction site has attracted more and more attention. By using BIM technology, Internet of Things technology, virtual technology, artificial intelligence, etc., safety accidents caused by management problems in the construction process can be solved. This paper puts forward the idea of exploring and applying smart construction site in the direction of construction quality management, hoping to provide experience for the development and further landing of smart construction site.
\end{abstract}

\section{Research background}

With the rapid development of China's economy, the society is in a period of rapid development, and the construction industry is also booming. The construction industry has become one of the important material production departments and pillar industries of our national economy. At the same time, due to the problem of construction quality, the construction industry is also a place where safety accidents occur frequently. The appearance of tall buildings everywhere can not only improve people's quality of life, but also bring potential safety hazards. Therefore, the construction quality requirements become the most important and basic requirements in buildings. Only when the construction quality meets the requirements can the construction industry achieve sustainable and healthy development.

Due to the complexity of modern buildings, it is easy to have quality problems in the construction process, which leads to the need for multiple repairs in the later period, which increases the workload and wastes resources. The quality problems of some concealed works are difficult to find, which may cause the loss of personnel and property during the subsequent use of buildings. If the personnel, equipment and materials can be detected in real time during the construction process, and problems can be found and repaired in time, the late time limit for a project change, rework and safety accidents can be avoided, and the quality of the project can be guaranteed.

\section{Study on Typical Types}

\subsection{Project background}

In 1994, a 48-meter-long bridge slab on the South Korean Shengshui Bridge, which was completed and opened to traffic for 15 years, fell into the river. The accident caused 32 deaths and 17 serious injuries. Six cars, including a bus full of students and office workers and a van full of police officers, fell into the Han River. Eventually, the deck of the bridge collapsed into the bottom of Hanjiang River, with 54 injured people and economic losses of hundreds of millions of yuan.

\subsection{Cause analysis of accident}

Shengshui Bridge is located in the southeast of Seoul, South Korea, crossing the Han River. This new bridge is a cantilever bridge, which is 1160 meters long and spans the Han River, the largest river in Korea. This project was also completed in South Korea within two years, and when the bridge was completed, many aspects paid attention to it. Because the bridge design concept of this construction is 
very advanced, the technology is also very advanced. At that time, the construction party said that the bridge would not need maintenance within 60 years. In the end, due to the problem of construction quality, the accident of Shengshui Bridge occurred.

In addition to the poor construction quality, the reasons for the collapse also include unreasonable bidding, management and maintenance, etc. The reasons for the collapse of Shengshui Bridge are emphasized from the aspects of design, construction and maintenance management:

(1) Design aspect

The design of Shengshui Bridge is unreasonable, and the stress of most members in the main truss span of the bridge exceeds the allowable value.

(2) Construction aspect

After investigating the design drawings and the fracture surface on site, it is found that the poor welding quality is one of the direct causes of the collapse of the bridge, and the effective bearing capacity of the original design is greatly reduced after construction. At the same time, errors in thickness and slope may cause stress concentration 40\% larger than the original design.

In addition to poor weld quality, another reason for the collapse may be that the bridge is not provided with regular and proper inspection and systematic maintenance management: fatigue cracks have been proved to gradually expand in a long period of time, which could have been clearly discovered, but the bridge is suddenly brittle due to lack of inspection.

In addition, the strong traffic load on the bridge has already exceeded the design requirements, and there is no daily regular inspection and no professional in steel bridge maintenance.

(4) Other aspects

The factors that play a potential role in bridge collapse can be summarized as follows: unreasonable construction plan and budget plan, lack of special skills and experts for inspection, insufficient maintenance management, insufficient investment in research and development, and insufficient concern of the state and society for engineering technology.

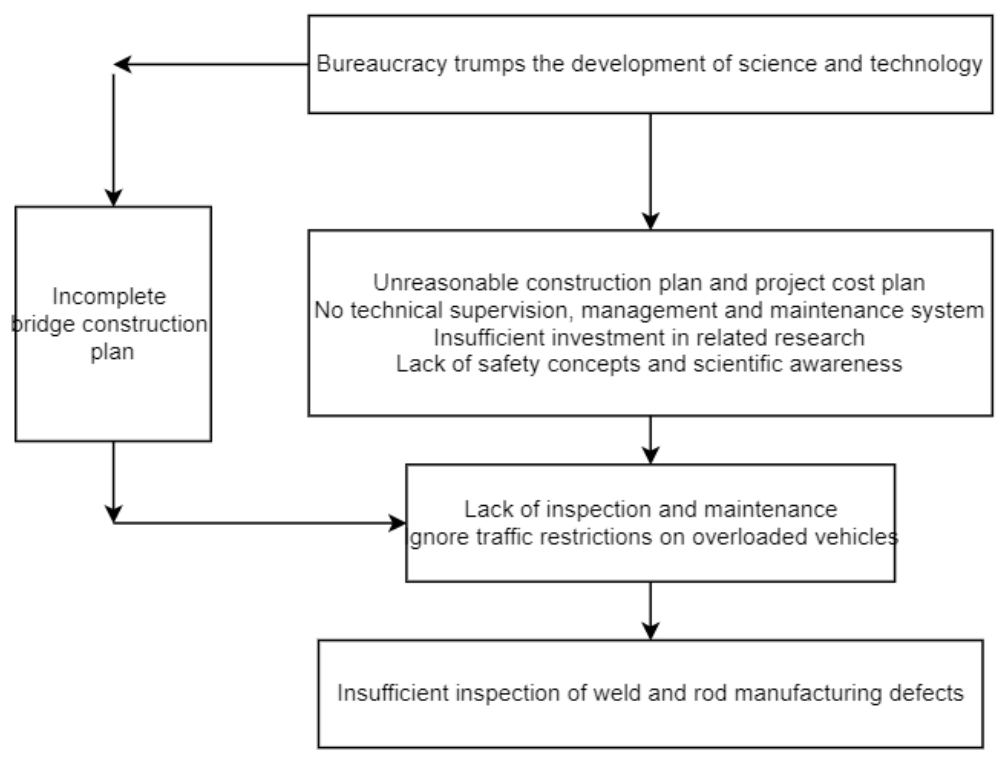

Figure 1. Reason summary

\section{Smart Site Solution to Improve Engineering Quality}

\subsection{Smart Construction Site}

Smart construction site is a complete set of project site management information system that supports site management, interconnection and coordination, intelligent decision-making and knowledge sharing around the whole life cycle of the project by means of information technology [3].Through the deep integration of advanced information technologies such as cloud computing, big data, Internet of Things, mobile Internet, artificial intelligence, BIM and other construction 
technologies, we can realize comprehensive perception of people and things, comprehensive intelligence of construction technology, interoperability of work, collaborative sharing of information, scientific analysis of decision-making, and intelligent pre-control of risks .The core of smart construction site is to improve the way of interaction between stakeholders and post personnel in order to improve the clarity, efficiency, flexibility and response speed of interaction. With the continuous improvement of informationize level and the deepening of construction enterprises in the field of information management, smart construction sites are being applied in more and more projects.

\subsection{BIM technology}

BIM technology is regarded as a tool for visualizing and coordinating construction work, avoiding errors and omissions, improving productivity and supporting the progress, safety, cost and quality management of construction projects [4].

BIM can be defined from a narrow and broad perspective [5].In a narrow sense, BIM can be regarded as composed of digital building models, including various building component information data; Broadly speaking, BIM, as an information resource pool, integrates the quality data, cost data and progress data of engineering projects, which can be divided into interrelated functional, information, technical and organizational problems [6].

BIM technology has many advantages, such as high synergy efficiency and high information integration, which attracts more and more attention from researchers and practitioners in the industry. According to the concept of BIM technology, the characteristics of BIM technology can be summarized: visualization, coordination and optimization [7].

Table.1. Technical characteristics of BIM [8]

\begin{tabular}{|c|c|}
\hline Characteristics & Main responsibilities \\
\hline Visualization & $\begin{array}{c}\text { Displays the three-dimensional outline of the whole } \\
\text { building, and also displays the spatial relationship } \\
\text { between the internal spaces of the building }\end{array}$ \\
\hline Synergy & $\begin{array}{c}\text { Through the coordination of information, all participants } \\
\text { in the project can communicate and avoid the problems } \\
\text { caused by poor communication }\end{array}$ \\
\hline Optimality & $\begin{array}{c}\text { It can provide all physical information, geometric } \\
\text { information, functional information and so on about the } \\
\text { construction process of the project, optimize the progress } \\
\text { and save the cost }\end{array}$ \\
\hline
\end{tabular}

The concept of BIM has been introduced into China's construction industry since 2003.In the early days, BIM technology was not used in many engineering projects in China, and there were few researches on BIM technology. At present, many enterprises have begun to pay attention to the application of BIM technology, which is being used on a large scale. BIM technology has been used in many large-scale projects, such as Shanghai Disney, Tianjin 117 Building, Zhuhai Opera House, Suzhou Zhongnan Center and National Convention and Exhibition Center, etc, all of which show that BIM technology is gradually developing to maturity in China.

\section{Construction of Smart Site}

\subsection{Safe construction}

Through BIM, the 3D model of the building can be built, and the data can be uploaded to the system through on-site inspection equipment, and the monitoring data can be analyzed in real time. If any abnormality is found, early warning can be given in time, thus effectively avoiding the resource loss and subsequent problems caused by rework and reconstruction. As dust, noise and other pollution will inevitably be caused in the process of building construction, BIM can be used to 
simulate the building, find the best installation point of testing equipment, and conduct dynamic monitoring to effectively reduce the pollution caused by construction.

\subsection{Personnel management}

We should formulate a reasonable employment plan and implement the real-name system management of labor service. Fingerprint entry shall be carried out for construction personnel during working hours, so as to ensure real-time monitoring of personnel flow of each type of work and convey personnel position information at all times. Clarify the responsibility of each working procedure, improve the responsibility traceability system, and prevent the behavior of cutting corners. At the same time, intelligent equipment can be used to train construction personnel, and the construction environment can be simulated in multiple directions to deepen the understanding of workers and improve the training quality.

\subsection{Mechanical equipment management}

Improve the registration system for the use of machinery, find hidden trouble points of equipment in time through intelligent equipment, and make feedback repairs in time. At the same time, in the construction process, synchronize the information such as the use status and parameters of the equipment, find out the unreasonable behavior of the equipment in time, and protect the mechanical equipment.

\section{Conclusion}

Based on the analysis of the current situation of construction quality in the field of construction engineering, and the analysis of the accident causes of the Shengshui Bridge in South Korea, this paper puts forward the idea of using smart construction sites to improve the construction quality. In this paper, the idea of construction quality inspection in smart construction site is still in the exploratory stage, and there are still many shortcomings. However, I believe that under the background of the gradual development of informationize, the management of construction quality by smart communities can be realized in the near future.

\section{References}

[1] EASEC-5 papers, building fot the 21st century, vol. 3.p. 2407 - 2415, July 1995.

[2] Editorial Board of China Construction Industry Informationize Development Report. Investigation and Analysis of Smart Site Application Status in Construction Industry-Excerpt from China Construction Industry Informationize Development Report (2017)-Smart Site Application and Development [R]. Chengdu: 2017:31-34.

[3] Zuppa D.Issa R.Suermann P.BIM's Impact on the Success Measures of Construction. Projects[C].International Workshop on Computing in Civil, 2009, 503-512.

[4] Volk R., Stengel J. Schultmann F. Building Information Modeling (BIM) for existing buildings Literature review and future needs [J]. Automation in Construction, 2014, 38: 109-127.

[5] Nie Shuangbing. BIM-based construction quality management model optimization research D]. Changsha: Central South University of Forestry and Technology. 2019. 